\author{
Women's Issues and Music Therapists: A Look Forward \\ Sandra Lynn Curtis \\ Concordia University
}

\begin{abstract}
Author Note
Sandra Curtis, PhD, MTA, MT-BC, Department of Creative Arts Therapies, Faculty of Fine Arts, Concordia University, Montréal, Québec, Canada.

Correspondence concerning this article should be addressed to Sandra Curtis, Department of Creative Arts Therapies, Faculty of Fine Arts, Concordia University, 1455 de Maisonneuve Blvd West, Montréal, Québec, Canada. Email: sandi.curtis@ concordia.ca
\end{abstract} 514-848-2424 ext 4679 (tel); 514-848-4969 (fax) 


\begin{abstract}
This study surveyed 1,890 American and Canadian music therapists with the purpose to examine present-day men and women music therapists' experiences as they compare with each other and as they compare with their 1990 counterparts in terms of their situations, their practices, their approaches, and their personal, work, and family concerns (Curtis, 1990). Quantitative and qualitative analyses of the structured and open-ended survey items revealed instances of commonalities and differences among the 682 respondents. In comparison to their 1990 counterparts, present-day women music therapists are significantly different in many instances; they are older, more educated, more often in academic settings, more satisfied with their career choice, and with many different concerns. Present-day men and women respondents' experiences reflect more commonalities, differing only in that the men are older, more educated, more often in academic settings, and higher paid. The present-day women and men are similar to each other and differ significantly from their 1990 counterparts with 68\%, 66\%, and $91 \%$ respectively feeling sex discrimination has a general impact. Similarly $31 \%$ of the present-day men and $25 \%$ of the women are familiar with feminist music therapy, as opposed to $16 \%$ in 1990 . Present-day men and women music therapists share a passion for their work, with $98 \%$ and $95 \%$ respectively recommending music therapy careers, as opposed to $56 \%$ in 1990.
\end{abstract}

Keywords: anti-oppressive practice, feminism, music therapy, women's issues 


\section{Women's Issues and Music Therapists: A Look Forward}

It has been some time since the first survey of music therapists that focused on women's issues (Curtis, 1990). This 1990 survey gathered opinions on a variety of women's issues, including response to feminist psychotherapy and - in combination with the first publication on feminist music therapy (Curtis, 2000) - "laid the groundwork for the field's current examination of feminist perspectives in music therapy" (Hahna, 2011, p. 293). Music therapy work building on this since has included a collection of writings representing diverse understandings of feminisms and touching upon such areas as theory, practice, research, supervision, and pedagogy (Hadley, 2006). Further works have included feminist music therapy practice with survivors of violence (Curtis, 2007, 2008, 2012, in press; Curtis \& Harrison, 2006), a feminist approach to the Bonny Method of Guided Imagery and Music (BMGIM) (Hahna, 2004), feminist music therapy pedagogy (Hahna, 2010, 2011; Hahna \& Schwantes, 2011), and feminism and anti-oppressive practice in music therapy (Baines, 2012).

While recently emerging, it should be noted that the impact of feminism has been late in music therapy in comparison to such sister disciplines as social work and psychology (Curtis, 2013; Edwards \& Hadley, 2007; Hadley \& Edwards, 2004). Furthermore, the degree of knowledge translation from individual researchers to the general population of music therapy practitioners is still unclear. The women`s issues survey of music therapists which examined understandings of the general population on these matters was not only the first survey of its kind; it was also the only one to date (Curtis, 1990).

A survey has since been conducted, however, of American music therapy educators, examining their views and use of feminist pedagogy and feminist music therapy (Hahna \& Schwantes, 2011). Results indicated that a majority $(67 \%, n=32)$ used "methods congruent with 
feminist pedagogy, however, most music therapists did not identify themselves as being feminist music therapists" (p. 307). Hahna and Schwantes concluded that "many of the reasons music therapists did not identify with the label feminist have not changed since Curtis' (1990) study" (p. 308), including concerns about the term, its meaning, misconceptions surrounding it, and fear of backlash. Hahna (2011) herself indicated her own similar issues: "It took me a long time before I could own the label feminist and I now understand this identity formation to be a journey" (p. 239). Ultimately, Hahna and Schwantes (2011) concluded that feminism has much to offer music therapy in practice and education, adding further, "What are the ethical implications of attempting to remain value-neutral in a society that is not value-neutral regarding gender (or age, class, culture, sociopolitical status, ability, sexual orientation, religion, etc.)?” (p. $313)$.

Given the recommendations arising from this recent survey of music therapy educators; given the general paucity of literature examining the issues, particularly across the general music therapy population at large; and given the length of time since the last related survey of all music therapy practitioners (Curtis, 1990), an examination of the current situation could provide invaluable information and insight. It could identify what has changed and what remains the same, documenting current knowledge of and attitudes towards women's issues and feminist understanding of those issues.

With this in mind, the present study was designed to examine the current situation and determine changes over time by surveying music therapists using the Curtis (1990) survey. This survey was quite extensive, covering a wide array of issues. A thoughtful analysis of all information gathered would be of greater scope than is possible within a single journal article. As a result, the report which follows focuses on the broader comparison of the current situation with 
that of 1990 and a comparison of present-day men and women music therapists. It is anticipated that a series of articles will follow that will focus more closely on comparison of the situations in Canada and the United States, as well as particulars concerning those practicing feminist music therapy and those practicing community music therapy.

\section{Method}

\section{Participants}

With ethics approval received from the university Human Research Ethics Committee (HREC), an email invitation to participate in the survey was sent to all professional members of the American Music Therapy Association (AMTA) and the Canadian Association for Music Therapy (CAMT) living in the United States and Canada. Individual email addresses were provided by the AMTA, while the CAMT national office sent out the survey invitation directly via email to its professional members. It should be noted that the Curtis (1990) survey was sent only to women music therapists. This was a purposeful and carefully-chosen delimitation in keeping with that study's purpose and intent (Curtis, 1990). With the current study, however, the decision was made to survey both women and men, with an interest in learning more about each group's experiences, their commonalities and differences.

Including all men and women AMTA and CAMT professional members, the survey was sent to 2,040 individuals (AMTA: 1,733; CAMT: 307); of those, 150 were returned because of non-functioning email accounts, making for a final total of 1,890. From those, 682 responded, for a return rate of $36 \%$. This return rate is a conservative one since there were some who were members of both the AMTA \& CAMT, making the total number smaller, and subsequently the return rate possibly greater. Because of the CAMT policy of not providing member emails, it was not possible to determine how many held dual membership. 


\section{Survey}

As indicated previously, the survey administered was the Curtis (1990) survey. Every attempt was made to keep it identical as possible with the following exceptions: (1) wording changed in two questions necessitated by the inclusion of men in the current survey (e.g., "Would you advise men and/or women to pursue a career in music therapy?"); (2) wording changed in a question about feminist music therapy (i.e., in the 1990 survey, reference was made instead to "feminist psychotherapy" since "feminist music therapy" had not yet been coined); (3) inclusion of questions about community music therapy in the current study, a term not yet coined in 1990 and added for interest sake on the part of the author); (4) inclusion of a question about music therapy theoretical orientation, added from a desire to gain further information; and (5) use of an online survey rather than the 1990 use of mailed hard copies.

The survey consisted of a 30-item questionnaire addressing professional music therapists' situations, concerns, and satisfaction related to their personal, work, and family lives. The survey included both structured and open-ended questions. Demographic information such as age, sex, ethnicity, geographic location, education, and family and work situations accounted for 16 survey items. Of the remaining items, six were structured and eight were open-ended. The structured items dealt with considerations in career choice (role model, earnings, full-time and/or part-time career opportunities, interest, and promotion opportunities), music therapy theoretical orientation, familiarity with community and feminist music therapies, and ranking of personal, family, and work concerns. For ranking of concerns, a 5-point Likert scale was used, with 1 indicating "not a problem" and 5 indicating "a very serious problem. The open-ended items dealt with impact of bias or discrimination, identification as community and/or feminist music therapists, role models, and music therapy career recommendations. 


\section{Procedures}

An email invitation to participate in the survey was sent to the identified participants with a link provided to the survey available online through Survey Monkey (2012) in either English or French. Informed consent was obtained though participation in the survey; participation was anonymous.

Quantitative analysis of the structured items of the survey was completed by an independent expert statistical consultant. The focus of the quantitative analysis included: Comparisons between the current survey results and those of 1990 for women participants; comparison between men and women's responses in the current survey; comparison between American and Canadian responses in the current survey; and comparison of discrimination concerns on the part of music therapists in general and those who self-identified as either feminist music therapists or community music therapists. A Chi-squared test was used, with ordinal regression for those ordered categorical variables with greater than two categories, in the analysis of contrasts on individual questions in terms of: 1990 compared to present day, men compared to women, and American compared to Canadian responses. A one-sample t-test was used in analysis of concerns ranked by music therapists in 1990 compared to those of present day.

Qualitative analysis of the survey's open-ended items was completed by an independent consultant expert, making use of the software NVivo 10 (QRS International, 2012). The consultant expert worked with sole responsibility for all aspects of the data analysis and the concomitant decision making involved in the process. Survey raw data were uploaded into NVivo, marking the fields to be analyzed and their description. Nodes were created for each item, as well as demographic data (e.g., male, female, Canada, U.S.). All answers to a specific 
item were coded under the respective node. After this initial coding, individual items were examined. All responses to a specific item were read to get an idea of possible nodes. Each response was then coded individually. At this point it was decided to code one answer - one node, unless the answer was very long and provided information about different issues, in which case parts of the answer were coded under different nodes. Also, some answers were coded under two or three nodes at the same time.

After this coding, a cluster analysis was used to visualize patterns by grouping nodes that shared similar words in the coded answers. A cluster analysis diagram was generated in NVivo using Pearson correlation coefficient to provide a graphical representation of nodes that shared very similar words in the coded answers and those where the answers were far apart. To generate data for the cluster analysis diagram, NVivo builds a table where the rows comprise words (top 100 words in Word frequency query results), the columns comprise each node that the query searches in and the cells comprise the number of times the row's word appears in the column's node. NVivo then calculates the similarity index between each pair of rows in the table, using Pearson correlation coefficient, where -1 is the least similar and 1 is the most similar. Using the calculated similarity index between each pair of items, NVivo clustered the nodes into most similar and least similar. In the second level of coding, the nodes that showed similarities in the cluster analysis were reviewed and if relevant merged.

After this cluster analysis, all nodes and coded content were reviewed to ensure the coding was still valid and to make any appropriate changes. Member checking was not possible in the process of this qualitative analysis because of the anonymous nature of the survey.

\section{Results}


In reviewing the survey results, it should be kept in mind that while there were 682 respondents, the number responding to individual questions occasionally varied by a small amount as not all respondents answered all items.

\section{Demographic Information}

Of the 682 survey respondents, $90 \%$ were women and $10 \%$ were men; this is in line with membership statistics from both the AMTA (2012) and the CAMT (2009). Additionally, 90\% were American and $10 \%$ Canadian.

The age breakdown of the survey respondents included $27 \%$ between 20 and 30, 28\% between 31 and 40, 16\% between 41 and 50, 21\% between 51 and 60, 7\% between 61 and 70 , and $1 \%$ over 70 years of age.

Of all respondents, 93\% were Caucasian/White, 3\% were Asian American/Canadian, 1\% African American/Canadian/Black, 1\% Multiracial, 1\% Hispanic/Latino(a), and 1\% other (including Native American/Canadian/First Nations, Inuit, and Pacific Islander); Five participants did not respond to this item.

Concerning their marital status, $71 \%$ were married/co-habitating, $22 \%$ single, and $7 \%$ separated, divorced, or widowed. Additionally, 53\% had no children, $16 \%$ had one child, $22 \%$ had two, and $8 \%$ had three or more children.

\section{Quantitative Analysis}

\section{0 to present day comparison - women music therapists.}

Because the original 1990 study surveyed only women music therapists, the comparison in this section is limited to women's responses then and now. This will be followed by a comparison of men's and women's experiences in the present day.

Women's situations. 
Over the intervening years since 1990, the lives of women music therapists reflect considerable change (see Table 1). There are a number of areas with significant differences between then and now. By and large, today women music therapists are older, with more married or co-habitating (70\% vs. $33 \%$ ) as opposed to single. They also have a higher educational level ( $8 \%$ with $\mathrm{PhDs}, 47 \%$ with MAs vs. $3 \%$ with $\mathrm{PhDs}$ and $30 \%$ with MAs). In terms of their work situation, less are working full-time now (63\% vs. 76\%), while more are working part-time by choice (22\% vs. $16 \%$ ). Salaries have increased over the spanning years, but this is to be expected given the time span; just what this means will be explored further in the comparison of presentday men and women music therapists.

\section{Insert Table 1 here}

\section{Women's practices.}

Currently, more women music therapists find themselves in academic settings than they did in 1990 (11\% vs. 5\%), while there are less in clinical (75\% vs. 94\%). In terms of those working in music therapy versus another field, not much has changed, with currently $89 \%$ in music therapy as opposed to $92 \%$ in 1990 . What attracts women to a career in music therapy has changed over the years, with more currently influenced by a role model and less choosing music therapy for general interest or financial considerations. Ultimately present-day women music therapists have greater satisfaction in the music therapy career choice, with significantly more recommending it to others than in 1990 (95\% vs. 56\%). However, many of those recommending music therapy careers included caveats with their recommendations (31\%): "[would recommend it] absolutely! But not for the money". This will be examined more fully in the Qualitative Analysis section of this article.

Women's approaches. 
The current survey examined more fully the theoretical orientation of music therapists than did its 1990 predecessor - looking at familiarity with feminist music therapy, but also examining familiarity with community music therapy as well as individual theoretical orientations. The 1990 survey found that $84 \%$ were unfamiliar with feminist psychotherapy, and $37 \%$ of those were opposed to it "in principle, or at least to the term feminist" (Curtis, 1990). The present-day women music therapists were significantly more familiar with feminist music therapy, although this was still small at $25 \%$. Furthermore, only $6 \%(n=37)$ self-identified as being feminist music therapists. In comparison, $44 \%$ were familiar with community music therapy, with $19 \%(n=127)$ self-identifying as being community music therapists. Specific to the current survey, respondents were provided the opportunity to identify their own music therapy theoretical orientation selected from a provided list of 14 (including an "other" category). These reflected considerable diversity, and respondents were able to select any number of orientations (see Figure 1). Of these, the most commonly identified were: Eclectic (42.4\%), cognitive behavioral (41.8\%), humanist (41.7\%), and applied behavioral analysis (36.6\%).

\section{Insert Figure 1 here}

\section{Women's concerns.}

Both the 1990 and present surveys gathered information on women music therapists' personal, family, and work concerns; these were assessed on a 5-point Likert scale. Comparisons between 1990 and present day concerns were made using the average ranks. While not ideal, this was the only option because that was all that was available from the 1990 data. This limitation is countered, however, by the strength of the robust number of survey respondents. From 1990 to the present, women music therapists' concerns showed significant differences across almost all of the areas (see Table 2). Their expressed concerns were significantly less than their 1990 
counterparts in the areas of: Childcare, detrimental effects of sex-role stereotyping, inadequate salary, insufficient involvement of partner in housekeeping, lack of advancement opportunity, lack of leisure time, lack of prestige, lack of professional recognition, lack of time/money for continuing education, relations with co-workers, self-confidence, sex bias/discrimination, and sexual harassment. Their expressed concerns were significantly greater than their 1990 counterparts in the areas of: Employment benefits, homophobia/heterosexism, job security, maternity and paternity leave, and racial bias/discrimination. There was no significance in their concerns around the burden of job and family responsibilities, fear of failure, or unemployment.

\section{Insert Table 2 here}

It is interesting to note that self-identification as either a feminist music therapist or a community music therapist had no effect on perception of racial or sex discrimination (as determined through ordinal regression analysis). On the other hand, salary had an effect on concerns around: Employment benefits, adequate salary, job security, advancement opportunity, leisure time, prestige, professional recognition, continuing education, co-worker relations, and unemployment. Salary did not, however, have an effect on concerns around the burden of job/family responsibilities, maternity leave, or paternity leave.

Having looked at the 1990 to present day quantitative comparison of women responses, attention will be directed in the section which follows to a closer look at the present-day, particularly in terms of commonalities and differences of men's and women's experiences.

\section{Male-female comparison present day.}

In reviewing the results in this comparison, it should be kept in mind that there was a relatively small number of men responding $(n=65)$ in comparison to women $(n=601)$. This small number is, however, reflective of the relative proportion of men in the music therapy 
profession. Quantitative analysis involved Chi-squared tests of all variables, with additional ordinal regression for those ordered categorical variables with greater than two categories. Unlike the 1990 to present day comparison, the male-female comparison for the present day reflected considerably less significant differences overall (see Table 3). Of the categories examined for comparison, there was no significant difference for 19: Familiarity with feminist music therapy, perception of racial discrimination, sexual harassment, and homophobiaheterosexism, and concerns around burden of job-family responsibilities, childcare, sex-role stereotyping, employment benefits, inadequate salary, job security, advancement opportunity, leisure time, prestige, continuing education, paternity leave, co-worker relations, and unemployment. There were significant differences for men and women within 9 categories: Age, education, work area, salary, familiarity with community music therapy, and concerns around fear of failure, involvement of partner in housekeeping, professional recognition, and maternity leave.

\section{Insert Table 3 here}

\section{Their situations.}

While the men's and women's situations were similar in many ways, there were important areas of differences. The men are significantly older, with more men in each of the categories of 41 to 50,51 to 60,60 to 70 , and over 70 years of age. In terms of education, male music therapists had further education with $25 \%$ holding doctoral degrees as opposed to $8 \%$ of women music therapists. Additionally the men's salaries were significantly greater than those of women music therapists (See Figure 2).

\section{Insert Figure 2 here}

\section{Their practices.}


Women and men music therapists were similarly situated with $83 \%$ of men remaining within the music therapy field and $89 \%$ of women. They differed significantly in terms of their employment status with $77 \%$ of men music therapists employed fulltime as opposed to $63 \%$ of women music therapists. Significant differences also existed in terms of their work area with $55 \%$ of the men and $75 \%$ of the women working in clinical practice; furthermore $38 \%$ of men worked in academic settings as opposed to $11 \%$ of women. The men and women reflected commonalities in their expressed satisfaction with music therapy careers, with $98 \%$ of men and $95 \%$ of women recommending others to pursue careers in music therapy. Both the men and the women included caveats with their recommendations (29\% and 31\% respectively) addressing issues such as salaries and personal qualifications.

\section{Their approaches.}

Men and women music therapists were similar in their lack of familiarity with feminist music therapy (31\% and $25 \%$ respectively). Both were more familiar with community music therapy, although men were significantly more familiar than the women (59\% as opposed to $44 \%$ ). In terms of identifying their own particular music therapy orientation, men and women similarly espoused a diversity of approaches. Within this diversity, the approaches most commonly identified by both were eclectic, cognitive behavioral, humanist, and applied behavioral analysis.

\section{Their concerns.}

Men and women music therapists shared commonalities across many of their personal, family, and work concerns. There were, however, a few instances of significant differences. Men had less concern than women in the areas of maternity leave, fear of failure, involvement of partner in housekeeping, and lack of professional recognition. These concerns for women 
averaged between "a minimal problem" and "somewhat of a problem". Greater concerns shared by both men and women included inadequate salaries and lack of leisure time.

\section{Qualitative Analysis}

Having looked at the quantitative comparative analyses, attention will be directed in this section to results of the qualitative analysis used with the open-ended survey items. As with the 1990 survey, many participants took time to write lengthy, thoughtful, and thought-provoking answers.

\section{Career considerations.}

Three open-ended survey items addressed participants' career consideration in terms of any male or female role models they might have had and recommendations they would make, if any, for music therapy careers. The importance of music therapists' role models should not be underestimated, particularly since the quantitative analysis indicated that these influenced career choices for approximately $20 \%$ of both the men and women today, as opposed to $0 \%$ in 1990 . With the current survey, men and women participants were asked about both male and female role models. In terms of male role models (with 475 women and 54 men responding), the primary thematic categories which emerged were: Family and friends (for 346 female, 31 male participants); teachers (for 158 female 17 male participants); other music therapists (for 19 women, 4 male participants); church ministers (for 23 female, 1 male participants); well-known musicians and music therapists (for 19 female, 9 male participants); and colleagues (for 16 female, 2 male participants). In terms of female role models (with 491 women and 53 men responding), the primary thematic categories which emerged were: Family \& friends (for 377 female, 35 male participants); teachers and administrators (for 128 female, 8 male participants); music therapy teachers, supervisors and mentors (for 74 female, 11 male participants); other 
music therapists (for 52 female, 9 male participants); spiritual mentors - including pastors, nuns, etc. (for 14 female, 3 male participants); and well-known musicians (for 9 female, 0 male participants).

In terms of recommending music therapy as a career for others, the quantitative analysis had indicated that $98 \%$ of men and $95 \%$ of women would recommend that others pursue music therapy careers; this was in stark contrast to the $56 \%$ in 1990. Qualitative analysis identified a number of common themes. For the small number not recommending music therapy careers, concerns surrounded salary and job availability. For those recommending such a career (with 530 women and 57 men responding), there was much passion expressed, but accompanied by some caveats. The themes which emerged included: Dedication and passion; financial, recognition, and job creation challenges; personal fulfillment; need for role models; need for prerequisite skills and interests; and the importance of the power of music. In the words of one participant: "Yes! We, as music therapists, do such innovative work that yields immediate results in the positive behaviors and enthusiastic feedback from our clients. If you believe that music has the power to heal and transform, then music therapy is the career for you."

\section{Impact of sex bias or discrimination.}

In the quantitative portion of the survey, participants ranked their concerns about sex bias or discrimination in their own lives, with the present-day men and women significantly less concerned than those in 1990 (average ranking of 1.25 versus 1.81 on a 5-point Likert Scale). Within the qualitative section, participants were asked through an open-ended question if they felt sex bias or discrimination had an impact in general. While in 1990, 91\% felt that there was an impact in general, this had changed over time with $66 \%(n=338)$ of the present-day women 
and $68 \%(n=35)$ of the present-day men respondents indicating that there was a general impact of sex bias or discrimination.

Of those indicating that there was no impact, three common themes emerged: That it did not affect them $(n=31)$ : "Not in my world"; that progress had been made $(n=4)$; and that it was a self-fulfilling prophecy ( $n=9)$ : "If we set out to look for it, it will". While some simply answered with "no", others reflected some emotional underpinnings: "I am so tired of hearing people going on about their personal agendas. Just get down to doing the best therapy you know how."

Of those indicating that sex bias/discrimination did still have an impact, themes that emerged included: Wages and status $(n=39)$; discrimination still exists despite progress made $(n=32)$; gender role stereotypes $(n=30)$; variations across fields and locations $(n=20)$; more covert nature of discrimination $(n=15)$; access to services and opportunities $(n=9)$; and positions of power $(n=7)$. Issues raised concerning wages and status involved pay inequities between men and women in general, as well as within female-dominated professions such as music therapy. Additionally, disproportionate representation of men in academic music therapy positions was identified as an issue. "Yes. It is interesting how many professors in music therapy are male and yet the vast majority of music therapists in the field are women." In speaking of the impact of gender-role stereotypes, one woman wrote: "In higher education, women are still secretaries, not faculty. Any time I'm with my husband (not a college professor) and we mention that we've moved to the area for the university, they look directly at him and ask what he teaches." Genderrole stereotypes as they impact men were also identified: "I feel that basic assumptions are made about people based on their gender. In my home, my children are raised by two fathers, and much of society works at the presumption of the nuclear family with one mother, father, brother, sister and dog by the door!” In speaking of the covert nature of present-day sexual 
discrimination, one woman wrote: "It is more subtle than it once was. It can be equally dangerous, but harder to pin down and document."

\section{Impact of other forms of discrimination.}

In response to an open-ended question other forms of discrimination (e.g., racism, homophobia/heterosexism, etc.), $75 \%$ of the women $(n=381)$ and $77 \%$ of the men respondents $(n=40)$ indicated that a general impact existed in present day. These percentages are greater than those for sexual discrimination; they are also reflective of the greater present-day concern of participants around racism and the lesser concern around sexism in comparison with their 1990 counterparts.

Of those indicating that there was no impact, responses were very brief, with the majority a simple "no." As a result, no themes emerged from these.

Of those indicating that other forms of discrimination did still have an impact, themes that emerged included: Lack of personal experience $(n=65)$; racism and homophobia $(n=25)$; attitudes and expectations $(n=24)$; impact of location $(n=24)$; discrimination despite progress made $(n=21)$; more covert nature of discrimination $(n=16)$; religious and political influences $(n=11)$; reverse discrimination $(n=10)$; societal equality and fairness $(n=5)$; and ageism $(n=3)$. A number indicated that despite experiencing discrimination personally, they acknowledged its existence for others. Issues of racism and homophobia were addressed specifically both in terms of personal experience and experience of others. In the words of one woman respondent: “As much as I wish that we were past all that, it's far from reality. I actually feel that racial tension and bias has gotten worse in recent years overall. And there is still plenty of homophobia around as well." Fear and hatred were two common themes emerging from participants responses in this area. As with sexual discrimination, a number of respondents commented on the increasingly 
covert nature of other forms of discrimination. Two emergent themes unique to the discussion of other discrimination were that of religious/political influences and reverse discrimination. In the words of one male respondent: "We may have become more accepting as a community, but there are still many smaller communities and individuals who are deeply rooted in their institutional belief structures and will never be able to move past judgment into acceptance." The theme of reverse discrimination emerged only from women participants' responses. These acknowledged discrimination, but also noted that it could be accompanied by reverse discrimination as well: "I think there is still an issue of racism and to some extent homophobia. In some ways there is reverse discrimination, giving a non-Caucasian worker the job to fill a quota. Why does the color of someone's skin have to matter, hire who is the most qualified. We are all equal." While looking at common themes surrounding other forms of discrimination, it should be noted that there was great diversity and many strong feelings expressed along the full continuum of these. From one viewpoint: "The term "homophobia" was designed to make a person who views homosexual behavior as unhealthy and abnormal, appear "intolerant" or confused. I disagree with this concept. Men and women were created differently for a reason. Homosexual behavior IS abnormal and persons who agree with this are NOT intolerant homophobes; they are realists." In contrast, another participant noted: "I think the general human tendency to separate "us" from "them" will always create tension, rifts and misunderstandings among people who can be construed as differing in any way. The best way to counter this natural inclination to separate is for people to learn more about those they think are "different" through first-hand shared experience."

\section{Feminist music therapy.}


The quantitative analysis in this area had determined that only $31 \%$ of the surveyed men $(n=19)$ and $25 \%$ of the surveyed women music therapists $(n=143)$ were familiar with feminist music therapy; only $16 \%$ of their 1990 counterparts were familiar with feminist psychotherapy. Those present-day music therapists who identified themselves as feminist music therapists accounted for $6 \%$ of both men $(n=4)$ and of women $(n=33)$. The qualitative analysis allowed for greater understanding of this in examining why participants did or did not identify themselves as feminist music therapists.

Of those who did not self-identify as feminist music therapists, a number of themes emerged. While some indicated a very brief "no" $(n=108)$, many others cited their lack of familiarity with the concept for not so identifying themselves (136 women, 12 men). Of these, four women indicated an interest in learning more: "I would like to learn more about it, because I think it has something to do with there being an equal division of power between therapist/client, and that sounds appealing to me". On the other hand, three indicated disagreement with the approach despite their unfamiliarity: "No. I'm not really sure what the term itself means, but, it implies excluding men. I don't really want to lump my clients and myself into a group. I like to practice by getting to know each unique individual within each moment of their process." Other reasons indicated for not identifying as feminist music therapists included: Its limiting perspective (5 women, 2 men); another focus of either their approach or their clients (18 women, 1 man); no need for this approach (2 women, 1 man); and agreement with the concept but not incorporating it in their practice (7 women, 1 man). "While I believe in some of the principles of feminism, they do not guide my decision making on how I practice music therapy."

Some themes emerged which were common to both those who identified as feminist music therapists and those who did not. These included: Issues around feminist identity (59 
women, 3 men); belief and orientation (16 women, 5 men); and incorporation of some elements of feminist music therapy (26 women, 4 men).

For those participants who identified as feminist music therapists, themes which emerged included: Support for empowerment (25 women, 4 men); support for equality (30 women, 4 men); and the previously mentioned feminist identity, belief and orientation, and incorporation of elements of feminist music therapy. In addressing empowerment, one man respondent wrote: "Yes, I see equality and social justice as enormous issues that face me as a music therapist and the people that I serve. Specifically, I see a need to promote the strengthening of people of color, all women, children, and people suffering from poverty." Another woman respondent indicated: Yes. I am a feminist music therapist. Feminism has been an important aspect of my personal growth process as a person, therapist, and educator . . . In the clinical setting, I value feminism because of its ability to work towards egalitarianism, an analysis of constructs (gender, race, sexual-orientation, ability-level, socioeconomic status, etc.), social activism, and a valuing of women's perspectives and ways of knowing. I've found feminism to be an integral part of my clinical practice and teaching and feel that it has much to offer music therapy as a field ... I am pleased that feminist theory is coming into the consciousness of music therapists currently. It is a groundbreaking time.

\section{Additional comments.}

The final open-ended item on the survey allowed participants to provide any additional comments. It was surprising that, despite the rather lengthy nature of this survey and despite the amount of time taken to provide lengthy responses, many participants ( 73 women, $10 \mathrm{men}$ ) took further time to provide additional comments at the survey's end. The issues addressed in this item were quite diverse but with some common themes emerging which included: The music 
therapy profession ( 24 women, 4 men); gender and discrimination issues (13 women and 2 men); and personal characteristics (6 women, 3 men). Additionally, participants commented on the survey itself (14 women, 1 man).

In their comments about the music therapy profession, $75 \%$ of both the men and women were unequivocally positive about their career choice; the remaining $25 \%$ indicated a need for improvement. One woman's words were reflective of many in her passion for music therapy: "This has been a very rewarding career for me and helped me to appreciate the intrinsic beauty of music ... I am still, after 30 years, touched by its powers and connection with the human spirit."

Comments on the theme of gender and discrimination were quite varied, including perception that they existed on one hand and that they did not on the other. A number also commented on the proportionate difference in numbers of men and women music therapists. Survey participants also commented on variety of personal characteristics necessary for success in music therapy. For some, these references stood alone $(n=5)$; others were made in light of overcoming financially-challenging times and in negating the impact of discrimination $(n=4)$.

In commenting on the survey itself, $100 \%$ of the men $(n=1)$ and $86 \%$ of the women $(n=$ 12) wrote positively; $14 \%$ of the women $(n=2)$ described the survey as biased. Those writing in support of the survey addressed both feminist music therapy and the broader issues. In the words of one woman participant: "It pleases my heart that there is continued scholarly exploration of the field of feminist music therapy, as it has much to offer us all." A man participant added: "This survey really seems to acknowledge many aspects of human life that have been omitted from the music therapy discussion for too long."

\section{Discussion}


The conclusion of the first music therapy survey on women's issues (Curtis, 1990) indicated that these issues “can no longer be seen as just women's issues. They have an impact in men's and women's lives, clinicians' and academicians' lives, and in our personal and professional lives" (p. 65). Findings of the current study are in keeping with this in its purposeful examination of both men and women music therapists' lives - their situations, their practices and approaches, and their personal, family, and work concerns. Comprehensive quantitative and qualitative data analyses permitted an indepth look at music therapists' present-day lives in their own right, as well as in comparison with their 1990 counterparts and with comparison between current men and women. These were characterized by instances of great diversity and great commonalities both within and between groups.

Music therapists' situations are reflective of considerable differences. Today, women music therapists are older, and more are married/co-habitating, hold higher educational levels, and work part-time by choice, with an increased number working in academic settings and a lesser number working in clinical settings; there are also less working full-time today. While present-day men and women music therapists' situations are similar in many ways, the men are older, with higher educational levels and greater salaries. Furthermore, significantly more of the men work in academic settings than do their women counterparts. Yet, despite significantly different salaries, men and women expressed similar job satisfaction, as well as similar concern levels about their salaries. The impact on salary of the complex relationship between these variables as well as gender-role stereotyping and discrimination can only be hypothesized at this point.

While personal, family, and work concerns differed significantly between 1990 and today, those for present-day men and women music therapists were fairly similar with a few 
notable exceptions (maternity leave, involvement of partner in housekeeping, and lack of professional recognition). The men and women had significantly less concern about sexism and significantly more concern about other forms of discrimination than their 1990 counterparts.

There is an emergent practice of feminist music therapy, which has as primary focus men's and women's empowerment through an understanding of the complex interactions of multiple forms of discrimination. Anti-oppressive practice is essential to the work and lives of feminist music therapists (Baines, 2012; Curtis, 2012). Yet men and women music therapists today are still relatively unfamiliar with feminist music therapy and what it might offer in this area.

In discussing these results, it is important to keep in mind existing study limitations and strengths. With the inclusion of men in the current study, wording of some survey items was of necessity changed; additionally the then-and-now comparisons were restricted to women participants. Furthermore, in the case of concern rankings, only aggregate data was available from 1990 as a result of some data loss over the intervening years. While the number of men respondents was small, it was reflective of their proportionate numbers in music therapy. The robust number of respondents overall, however, lends great strength to this study.

Regardless of acknowledged challenges, today's music therapists - both men and women - share a common passion and enthusiasm for their chosen profession. With $98 \%$ of men and $95 \%$ of women music therapists recommending music therapy careers to others today, they are significantly more satisfied with the music therapy profession than their 1990 counterparts.

Having examined the lives of today's music therapists and the commonalities and differences with those of 1990 , what can we look forward to in the future? With a shared passion for the music therapy profession despite challenges, with the willingness of so many to explore 
important issues through participation in this survey, and with the potential offered by emergent feminist music therapy to address some important challenges still facing our profession, much is possible. Increased knowledge translation about feminist music therapy, moving beyond any misconceptions or stereotypes related to the term, could be very beneficial, as could an ongoing dialogue on these important and at times challenging issues. Learning with and from our sister creative arts therapies in this area could offer mutual benefits. The dialogue, opened in 1990, has been joined by the many men and women music therapists of today who took such time and care to eloquently express themselves in the current survey. More of their experiences will be explored in a series of follow-up articles which will focus on the situations particular to Canada and the United States, as well as more detailed examination of the experiences of individuals practicing feminist music therapy and community music therapy. It is hoped that these will motivate others to join in and carry the dialogue - and the work - further. 


\section{References}

American Music Therapy Association. (2012). AMTA sourcebook. Silver Spring, MD: Author.

Baines, S. (2012). Music therapy as an anti-oppressive practice. The Arts in Psychotherapy, 40 (1), 1-5.

Canadian Association for Music Therapy. (2009). CAMT Sourcebook. Toronto, ON: Author.

Curtis, S.L. (1990). Women's issues and music therapists. Music Therapy Perspectives, 8, 61-66.

Curtis, S. L. (2000). Singing subversion, singing soul: Women's voices in feminist music therapy. (Doctoral dissertation, Concordia University, 1997). Dissertation Abstracts International, 60, (12-A), 4240.

Curtis, S.L. (2006). Feminist music therapy: Transforming theory, transforming lives. In S. Hadley (Ed.) Feminist perspectives in music therapy, 227-244. Philadelphia, PA: Barcelona Publishers.

Curtis, S. (2007). Claiming voice: Music therapy for childhood sexual abuse survivors. In S. Brooke (Ed.), The use of creative arts therapies with sexual abuse survivors. (pp. 196206). Springfield, IL: C. C. Thomas.

Curtis, S. (2008). Songs of freedom: Music therapy for women survivors of domestic violence. In S. Brooke (Ed.), Creative arts therapies and domestic violence, (pp. 121 - 135). Springfield, IL: C. C. Thomas.

Curtis, S. L. (2012). Music therapy and social justice: A personal journey. Arts in Psychotherapy. 39 (3), 209-213. doi:10.1016/j.aip.2011.12.004

Curtis, S. L. (2013). Sorry it has taken so long: Continuing feminist dialogues in music therapy. Voices: A World Forum for Music Therapy, 13(1).

Curtis, S. L. (in press). Women survivors of abuse and developmental trauma. In Ken 
Bruscia (Ed.), Guidelines for Music Therapy Practice. 8. Gilsum, NH: Barcelona Publishers.

Curtis, S., \& Harrison, G. (2006). Empowering women survivors of violence: A collaborative music therapy-social work approach. In S. L. Brooke (Ed.), Creative modalities for therapy with children and adults. (pp. 195-204). Springfield, IL: C. C. Thomas.

Edwards, J., \& Hadley, S. (2007). Expanding music therapy practice: Incorporating the feminist frame. The Arts in Psychotherapy, 34(3), 199-207.

Hadley, S. (Ed.). (2006). Feminist perspectives in music therapy. Gilsum, NH: Barcelona Publishers.

Hadley, S., \& Edwards, J. (2004). Sorry for the silence: A contribution from feminist theory to the discourse(s) within music therapy. Voices: A World Forum for Music Therapy, 4 (2). Retrieved October 28, 2012, from https://normt.uib.no/index.php/voices/article/view/177/136

Hahna, N.D., (2004). Empowering women: A feminist perspective of the Bonny Method of Guided imagery and Music and intimate partner violence. (Unpublished master's thesis). Radford University, Radford, VA.

Hahan, N.D. (2010). A survey of music therapy educators' use of feminist pedagogy: A pilot study. Unpublished manuscript. Lesley University, Cambridge, MA.

Hahna, N. D. (2011). Conversations from the classroom: Reflections on feminist music therapy pedagogy in teaching music therapy (Doctoral dissertation). ProQuest LLC.

Hahna, N.D., \& Schwantes, M. (2011). Feminist music therapy pedagogy: A survey of music therapy educators. Journal of Music Therapy, 48 (3), 289-316.

QSR International (2011). NVivo 10. Retrieved from 
http://www.qsrinternational.com/products.aspx.

Survey Monkey (2012). Survey Monkey homepage. Retrieved from http://www.surveymonkey.com/ 


\section{A LOOK FORWARD}

Figure 1.

Present-day Theoretical Orientation: Women Music Therapists

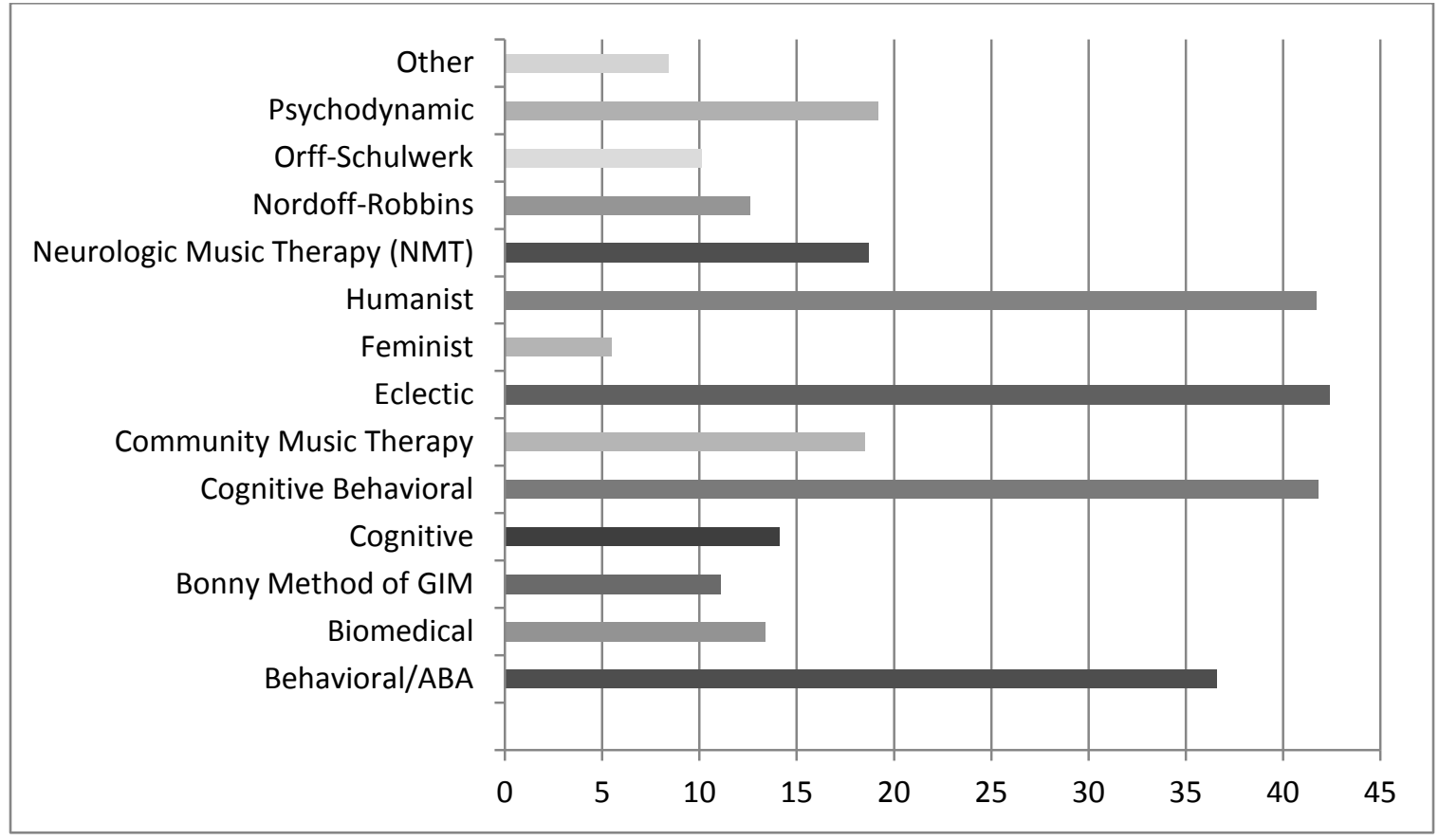

Percentage of responses, with participants able to select any number of orientations. 
Figure 2.

Present-day Salaries: Men and Women Music Therapists

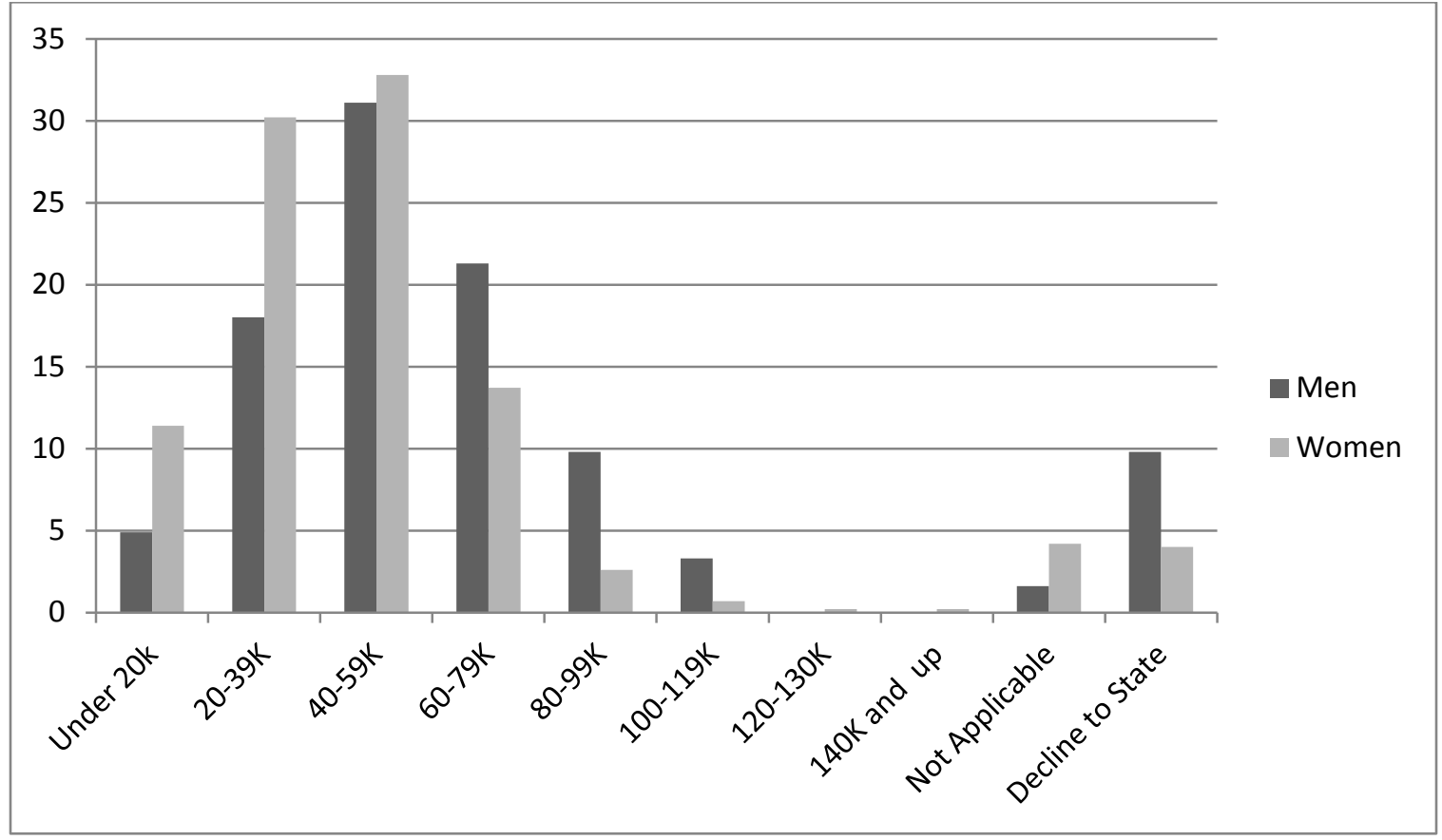




\section{A LOOK FORWARD}

Table 1.

1990 to Present-day Comparison: Women Music Therapists

\begin{tabular}{lcrrr}
\hline \multicolumn{1}{c}{ Survey Item } & Test & Value & $p$-value & $\begin{array}{c}\text { Direction of Significant Difference for } \\
\text { Present-Day Women }\end{array}$ \\
\hline Age & $\mathrm{X}^{2}$ & 169.68 & $<0.001$ & Older \\
$\quad \mathrm{T}$ & 11.15 & $<0.001$ & More are married/cohab vs. single \\
Age & $\mathrm{X}^{2}$ & 212.63 & $<0.001$ & Higher educational level \\
Edurital Status & $\mathrm{X}^{2}$ & 59.06 & $<0.001$ & \\
$\quad \mathrm{~T}$ & 5.613 & $<0.001$ & More are familiar with Fem Psy/FMT \\
$\quad$ Educational degree & $\mathrm{X}^{2}$ & 17.016 & $<0.001$ & Less are FT; more are PT by choice \\
Feminist Psychotherapy/FMT & $\mathrm{X}^{2}$ & 42.2 & $<0.001$ & \\
Employment Status & $\mathrm{X}^{2}$ & 8.55 & 0.003 & More in academic; less in Clinical \\
Work Situation & $\mathrm{X}^{2}$ & 120.93 & $<0.001$ & Less feel sex discrimination has an impact \\
Primary Work & $\mathrm{X}^{2}$ & 42.54 & $<0.001$ & More role model; less for interest or \$ \\
Sex bias/discrimination & $\mathrm{X}^{2}$ & 370.5 & $<0.001$ & More recommend MT Career \\
Career Choice & $\mathrm{X}^{2}$ & 285.95 & $<0.001$ & \\
Pursue Career in MT & & & & \\
\hline
\end{tabular}




\section{A LOOK FORWARD}

Table 2.

1990 to Present-day Comparison: Personal, Family, \& Work Concerns: Women Music Therapists

\begin{tabular}{|c|c|c|c|c|c|}
\hline Concern & $\begin{array}{c}\text { Mean } \\
1990\end{array}$ & $\begin{array}{c}\text { Mean } \\
\text { Present }\end{array}$ & $\mathrm{T}$ & $p$-value & Direction of Significant Difference \\
\hline Burden of job \& family responsibilities & 2.28 & 2.39 & 2.17 & 0.031 & No significant difference \\
\hline Childcare & 2.07 & 1.65 & -7.45 & $<0.001$ & Less concern in present \\
\hline Detrimental effects of sex-role stereotyping & 1.82 & 1.49 & -8.74 & $<0.001$ & Less concern in present \\
\hline Employment benefits & 1.81 & 2.06 & 4.39 & $<0.001$ & More concern in present \\
\hline Fear of failure & 2.03 & 2.00 & -0.76 & 0.450 & No significant difference \\
\hline Homophobia /heterosexism & 0.00 & 1.17 & 44.00 & $<0.001$ & More concern in present \\
\hline Inadequate salary & 3.01 & 2.49 & -9.31 & $<0.001$ & Less concern in present \\
\hline $\begin{array}{l}\text { Insufficient involvement of partner in } \\
\text { housekeeping }\end{array}$ & 2.00 & 1.71 & -6.37 & $<0.001$ & Less concern in present \\
\hline Job security & 2.07 & 2.29 & 4.18 & $<0.001$ & More concern in present \\
\hline Lack of advancement opportunity & 3.22 & 2.39 & -14.29 & $<0.001$ & Less concern in present \\
\hline Lack of leisure time & 2.68 & 2.46 & -4.17 & $<0.001$ & Less concern in present \\
\hline Lack of prestige & 2.76 & 1.99 & -16.25 & $<0.001$ & Less concern in present \\
\hline Lack of professional recognition & 3.02 & 2.31 & -13.41 & $<0.001$ & Less concern in present \\
\hline Lack of time/money for continuing education & 3.10 & 2.78 & -5.52 & $<0.001$ & Less concern in present \\
\hline Maternity leave & 0.00 & 1.70 & 26.42 & $<0.001$ & More concern in present \\
\hline Paternity leave & 0.00 & 1.40 & 24.89 & $<0.001$ & More concern in present \\
\hline Relations with co-workers & 2.00 & 1.65 & -8.95 & $<0.001$ & Less concern in present \\
\hline Racial Bias/Discrimination & 0.00 & 1.19 & 45.97 & $<0.001$ & More concern in present \\
\hline Self-confidence & 2.03 & 1.77 & -6.87 & $<0.001$ & Less concern in present \\
\hline Sex bias/discrimination & 1.81 & 1.25 & -20.94 & $<0.001$ & Less concern in present \\
\hline Sexual harassment & 1.45 & 1.09 & -22.53 & $<0.001$ & Less concern in present \\
\hline Unemployment & 1.49 & 1.46 & -0.62 & 0.534 & No significant difference \\
\hline
\end{tabular}

Note: A one-sample T-test was used for analysis of all concerns which were rated on a 5-point Likert scale, with 1 indicating “not a problem” and 5 indicating "a very serious problem”. 
Table 3.

Male-Female Comparison Present Day (Women: $n=601$; Men: $n=65$ )

\begin{tabular}{|c|c|c|c|c|}
\hline Variable & $\begin{array}{l}\text { Sample } \\
\text { Size }\end{array}$ & $\begin{array}{c}\text { Chi- } \\
\text { squared }\end{array}$ & $p$-value & Direction of Significant Difference \\
\hline Age & 664 & 15.704 & 0.008 & Men are older \\
\hline Community Music Therapy & 635 & 5.082 & 0.024 & More men familiar with CoMT \\
\hline Feminist Music Therapy & 635 & 1.128 & 0.288 & No significant difference \\
\hline Work Area & 624 & 34.646 & $<0.001$ & More men than women in academic position, less in clinical practice \\
\hline Salary & 577 & 20.398 & 0.005 & Men have greater salaries than women \\
\hline Burden Job Family & 614 & 3.856 & 0.570 & No significant difference \\
\hline Childcare & 616 & 8.720 & 0.121 & No significant difference \\
\hline Sex Role Stereotyping & 615 & 2.475 & 0.780 & No significant difference \\
\hline Employment Benefits & 618 & 3.045 & 0.693 & No significant difference \\
\hline Fear of Failure & 616 & 9.314 & 0.097 & Fear of failure is less of a concern for men than women \\
\hline Homophobia-Heterosexism & 613 & 3.609 & 0.607 & No significant difference \\
\hline Inadequate Salary & 612 & 6.855 & 0.232 & No significant difference \\
\hline Partner Housekeeping & 617 & 9.948 & 0.077 & \\
\hline Ordinal regression & & & 0.011 & Involvement of partner in housekeeping is less of a concern for men \\
\hline Job Security & 617 & 9.059 & 0.107 & No significant difference \\
\hline Advancement Opportunity & 618 & 8.617 & 0.125 & No significant difference \\
\hline Leisure Time & 616 & 5.395 & 0.370 & No significant difference \\
\hline Prestige & 615 & 4.720 & 0.451 & No significant difference \\
\hline Professional Recognition & 617 & 11.102 & 0.049 & Professional Recognition is less of a concern for men than women \\
\hline Continuing Education & 618 & 10.879 & 0.054 & No significant difference \\
\hline Maternity Leave & 616 & 13.766 & 0.017 & Maternity Leave is less of a concern for men than women \\
\hline Paternity Leave & 613 & 7.850 & 0.165 & No significant difference \\
\hline Co-worker Relations & 609 & 2.902 & 0.715 & No significant difference \\
\hline Racial Discrimination & 616 & 1.494 & 0.914 & No significant difference \\
\hline Self Confidence & 616 & 9.030 & 0.108 & No significant difference \\
\hline Sex Discrimination & 616 & 1.255 & 0.939 & No significant difference \\
\hline Sexual Harassment & 616 & 2.387 & 0.793 & No significant difference \\
\hline Unemployment & 608 & 4.969 & 0.420 & No significant difference \\
\hline
\end{tabular}

